\title{
QUALIDADE FISIOLÓGICA DE SEMENTES DE MAMONA CLASSIFICADAS POR TAMANHO ${ }^{1}$
}

\author{
JACSON ZUCHI², LUIS EDUARDO PANOZZO², ELAINE HEBERLE², \\ DENISE CUNHA FERNANDES DOS SANTOS DIAS ${ }^{3}$
}

\begin{abstract}
RESUMO - O tamanho da semente, em muitas espécies, pode ser um indicativo de sua qualidade fisiológica. O objetivo neste trabalho foi avaliar o desempenho fisiológico de sementes de mamona classificadas por tamanho. O experimento foi conduzido no Laboratório de Pesquisa de Sementes do Departamento de Fitotecnia da Universidade Federal de Viçosa e foram utilizadas sementes de quatro cultivares de mamona, IAC 226, IAC 80, Al Guarany 2002 e BRS 188 Paraguaçu, oriundas de todos os racemos da planta. As sementes foram classificadas em três peneiras, segundo a cultivar e foram avaliadas por meio dos testes de primeira contagem de germinação, germinação final, envelhecimento acelerado, comprimento de plântula, sistema radicular e parte aérea, massa de matéria fresca e massa de matéria seca. Nas cultivares IAC 226 e BRS 188 Paraguaçu há tendência de as sementes menores apresentarem maior velocidade e porcentagem final de germinação, porém não para as cultivares IAC 80 e AL Guarany 2002.
\end{abstract}

Termos para indexação: Ricinus communis L., beneficiamento, peneira, germinação.

\section{PHYSIOLOGICAL QUALITY OF CASTOR BEAN SEEDS CLASSIFIED BY SIZE}

\begin{abstract}
Seed size in many species may be an indication of their physiological quality. The objective of this study was to evaluate the physiological performance of castor bean seeds sorted by size. The experiment was conducted at the Seed Research Laboratory of the Department of Plant Science at the Federal University of Viçosa. Seeds of four castor bean cultivars, IAC 226, IAC 80, Al Guarany 2002 and BRS 188 Paraguaçu were used. The seeds were harvested from all the plant racemes and classified into three different seed sizes for each cultivar. Tests were conducted to evaluate germination and vigor: germination at the $4^{\text {th }}$ day, germination at the $7^{\text {th }}$ day, accelerated ageing, seedling length of roots and shoots and fresh and dry weights of the seedlings. Based on the results for IAC 226 and BRS 188 Paraguaçu there is a tendency for smaller seeds to show higher speeds and final percentage of germination but this was not the case for the IAC and 80 AL Guarany 2002.
\end{abstract}

Index terms: Ricinus communis L., processing, sieve, germination.

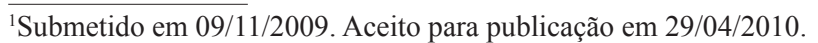

${ }^{2}$ Eng. Agr., Doutorando em Fitotecnia, Departamento de Fitotecnia, UFV, Avenida P.H. Rolfs s/n, CEP:36570-000, Viçosa,MG. E-mail: jacson. zuchi@ufv.br; lepanozzo@gmail.com; naniengel@yahoo.com.br.
${ }^{3}$ Eng. Agr. Dr. Prof. Associado, Departamento de Fitotecnia, UFV, Av. P.H. Ralfs, s/n, CEP: 36570-000,Viçosa ,MG. Bolsista CNPq. E-mail: (dcdias@ufv.br). 


\section{INTRODUÇÃO}

O tamanho da semente, em muitas espécies, é indicativo de sua qualidade fisiológica (Popinigis, 1977). A classificação de sementes por tamanho pode se constituir em estratégia para aumentar a produtividade, pois o tamanho da semente pode afetar a germinação, o vigor das plântulas e a produção de grãos. Além disso, sementes de tamanho uniforme aumentam a precisão da semeadura mecânica (Krzyzanowski et al., 1991).

Há trabalhos com trigo, que relacionam o tamanho da semente com o desenvolvimento de plântulas (Peterson et al., 1989, Grieve e Francois, 1992 e Mian e Nafziger, 1994.) Plântulas originadas de sementes grandes apresentam maior estatura e acumulam mais massa seca, quando comparadas com plântulas originadas de sementes menores (Lafond e Baker, 1986; Grieve e Francois, 1992), além de emitirem maior quantidade de perfilhos (Peterson et al., 1989; Mian e Nafziger, 1994) e raízes (Peterson et al., 1989). Sementes grandes de trigo produzem plântulas maiores em condições de baixa disponibilidade hídrica (Mian e Nafziger, 1994), alta salinidade (Grieve e Francois, 1992) e em semeadura profunda (Mian e Nafziger, 1994).

A produção de biomassa na parte aérea e no sistema radiculare o acúmulo de fósforo emplântulas degenótipos de feijoeiro está correlacionadas com a massa da semente (Yan et al., 1995). Evidências indicam que sementes pequenas de soja apresentam reduzida emergência e originam plantas menores, porém, a superioridade das sementes grandes no rendimento de grãos não foi suficientemente comprovada (Lima e Carmona, 1999). Estudos comparando genótipos de feijoeiro apresentando sementes de diferentes tamanhos indicam correlação negativa entre tamanho de semente e rendimento de grãos, embora a magnitude deste efeito varie com o ambiente (White e González, 1990). Genótipos de feijoeiro, com sementes grandes, apresentam menor taxa de crescimento relativo e rendimento de grãos do que genótipos de sementes pequenas (White et al., 1992).

Em soja, a variação de tamanho de sementes entre lotes de sementes está relacionada com o tamanho das células cotiledonares e não com seu número (Hirshfield et al., 1993). No entanto, a variabilidade em tamanho não afeta a composição química das sementes de soja (Tinius et al., 1993), mas em amendoim sementes maiores apresentam maior conteúdo de proteína, o que confere maior vigor às mesmas (Siyasubramanian e Ramakrishnam, 1974). Burris et al. (1973), trabalhando com soja, concluíram que sementes maiores geram plantas com maior área foliar e altura, além de maior produtividade. Kolak et al. (1992), também concluíram que o tamanho de sementes de soja está positivamente correlacionado com fatores de produção, como altura de plantas, número de vagens e número de sementes, mas não com a produtividade.

Tem sido observada grande variabilidade no tamanho das sementes de mamona, variação esta que parece estar relacionada tanto ao genótipo quanto à ordem de sua frutificação na planta. Nesse sentido, verifica-se que geralmente os racemos mais tardios produzem sementes de menor tamanho.

O desenvolvimento da cadeia produtiva da mamona ainda é incipiente e carece de mais estudos relacionados às características físicas, fisiológicas e sanitárias das sementes, para a consolidação de um setor sementeiro forte nessa área. Sendo assim, trabalhos de pesquisa, incluindo o beneficiamento, onde estão envolvidas as propriedades físicas das sementes tais como a forma, o tamanho, o volume, a densidade e a área são imprescindíveis para o dimensionamento de máquinas e equipamentos agrícolas (Monhsenin, 1970), consequentemente, de grande importância para o fomento desta cadeia. Dessa forma, objetivando buscar mais informações a respeito do assunto, avaliou-se nesse trabalho, o desempenho fisiológico de sementes de mamona classificadas por tamanho.

\section{MATERIAL E MÉTODOS}

O experimento foi conduzido no Laboratório de Pesquisa de Sementes do Departamento de Fitotecnia da Universidade Federal de Viçosa (UFV), durante os meses de agosto e setembro de 2008.

Foram utilizadas quatro cultivares de mamona, IAC 226, IAC 80, AL Guarany 2002 e BRS 188 Paraguaçu, as quais apresentam diferenças de ciclo, porte e deiscência das vagens. As cultivares AL Guarany 2002 e IAC 226 possuem ciclo de 180 dias, porte médio e fruto indeiscente. A cultivar IAC 80 apresenta ciclo de 240 dias, porte alto e frutos semideiscentes e a cultivar BRS 188 Paraguaçu apresenta ciclo de 230 a 250 dias, porte médio/alto e frutos semideiscentes.

As sementes de mamona utilizadas neste estudo foram produzidas nas áreas experimentais da Embrapa Clima Temperado, em Pelotas, Rio Grande do Sul, e enviadas à UFV em maio de 2008. As sementes de cada cultivar, colhidas de todos os ramos, quando $70 \%$ dos frutos se encontravam secos, foram selecionadas por peso, forma e aparência, manualmente em laboratório, a fim de 
homogeneizá-las e constituir um único lote. Após isto, as sementes foram classificadas em três peneiras, segundo a cultivar, por agitação manual, durante um minuto. Para tanto, foram utilizadas as seguintes peneiras de orifícios oblongos para a cultivar IAC 226 , peneiras $5,25 \times 19 \mathrm{~mm}$, $5,75 \times 19 \mathrm{~mm}$ e $6,25 \times 19 \mathrm{~mm}$; para a cultivar IAC 80 , $6,25 \times 19 \mathrm{~mm}, 7 \times 17 \mathrm{~mm}$ e 7,5x19 mm; e para a cultivar AL Guarany 2002, 5,75x19 mm, 6,25x19 mm e 6,5x15 mm. Peneiras de orifício circular de $10 \mathrm{~mm}, 12 \mathrm{~mm}$ e $13 \mathrm{~mm}$ foram utilizadas para classificar as sementes da cultivar BRS 188 Paraguaçu.

Para avaliar a qualidade fisiológica das sementes, foram realizados testes de primeira contagem de germinação, germinação, envelhecimento acelerado, comprimento da plântula, do sistema radicular e da parte aérea, massa de matéria fresca e massa de matéria seca da plântula. Avaliaram-se, em cada teste, 600 sementes, distribuídas em três repetições estatísticas de 200 sementes, perfazendo 12 rolos de 50 sementes. Para o teste de desempenho de plântulas utilizaram-se 240 sementes, distribuídas em três repetições estatísticas de 80 sementes, perfazendo 12 rolos de 20 sementes.

No teste de germinação, as sementes foram distribuídas em papel tipo germitest umedecido com água destilada em quantidade equivalente a 2,5 vezes o seu peso, confeccionando-se rolos. Estes foram acondicionados em germinador a $25^{\circ} \mathrm{C}$, realizando-se contagens aos sete e 14 dias. Os resultados foram expressos em porcentagem de plântulas normais obtidas na primeira e última contagem de germinacao.

O teste de envelhecimento acelerado foi realizado distribuindo-se 100 sementes sobre a tela acoplada à caixa gerbox, a qual continha no fundo $40 \mathrm{~mL}$ de água destilada. As caixas foram tampadas e mantidas em incubadora do tipo BOD, a $42{ }^{\circ} \mathrm{C}$, por 48 horas (Mendes, 2007). Após este período procedeu-se a semeadura das sementes conforme descrito para o teste de germinação, realizando-se uma única contagem aos sete dias, sendo os resultados expressos em porcentagem de plântulas normais.

No teste de comprimento de plântulas semearamse 20 sementes, em rolo de papel, dispostas em linha e alternadamente, com a carúncula voltada para baixo, seguindo o mesmo procedimento do teste de germinação, com avaliação aos 14 dias. Após esse período mediu-se o sistema radicular e a parte aérea das plantas normais e, em seguida, pesaram-se as plantas normais de cada repetição com precisão de $0,001 \mathrm{~g}$, sem a retirada do endosperma, e os resultados expressos em $\mathrm{mg} /$ plantula. Os resultados foram expressos em mm/plântula. As plântulas normais obtidas neste teste foram então colocadas dentro de sacos de papel e secadas em estufa a $70{ }^{\circ} \mathrm{C}$, com circulação forçada de ar por 72 horas para determinação da massa seca. Os resultados foram expressos em $\mathrm{mg} /$ plântula.

$\mathrm{O}$ delineamento experimental utilizado foi $\mathrm{o}$ inteiramente casualizado. Os dados foram submetidos à análise de variância no programa estatístico SAS (Versão 9.0, 1998) e as médias dos tratamentos, em cada cultivar, comparadas pelo teste de Tukey a $5 \%$ de probabilidade.

\section{RESULTADOS E DISCUSSÃO}

A velocidade de germinação (Tabela 1), avaliada pela primeira contagem do teste de germinação, foi significativamente maior nas sementes de menor tamanho nas cultivares IAC 226 e BRS 188 Paraguaçu, peneiras $5,25 \times 19$ e 10 respectivamente. Nas demais cultivares não houve diferenças significativas na velocidade de germinação das sementes classificadas por tamanho. Verifica-se, para a cultivar IAC 226 que a porcentagem de germinação na primeira contagem das sementes da peneira $5,25 \times 19$ foi 15 pontos percentuais (pp) superior ao valor obtido para as sementes da peneira $5,75 \times 19$ e $12 \mathrm{pp}$ superior ao observado para as sementes de peneira 6,25x19. Na cultivar BRS 188 Paraguaçu, a diferença da primeira contagem das sementes da peneira $10 \mathrm{em}$ relação as peneiras 12 e 13 foram de $16 \mathrm{pp}$ e $13 \mathrm{pp}$, respectivamente (Tabela 1). Sung (1992) relatou que as sementes pequenas de soja também emergem mais rapidamente e com sistema radicular mais desenvolvido, e, segundo os autores, provavelmente por necessitarem de menor quantidade de água para germinar. A maior velocidade de germinação de sementes pequenas de soja deve-se ao maior vigor das mesmas, mesmo que menos viáveis (Sung, 1992). Sementes de palmeira Jussara (Euterpe edulis Mart.) de tamanho menor têm a germinação menos prejudicada do que as sementes de tamanho médio e maior com o aumento do período de secagem (Martins et al., 2009).

Sementes menores (peneira $5,25 \times 19$ ) da cultivar IAC 226 tiveram germinação superior às sementes maiores (peneira 6,25x19), o que também foi observado para a cultivar BRS 188 Paraguaçu, cujas sementes retidas nas peneiras de 10 e 12 apresentaram melhor qualidade, ao passo que na cultivar IAC 80 , as sementes maiores (peneira $6,25 \times 19)$ apresentaram maiores valores de germinação (Tabela 1). O tamanho não influenciou a germinação das sementes da cultivar AL Gurany 2002, semelhante ao 
ocorrido para a primeira contagem da germinação das sementes da cultivar IAC 80 (Tabela 1). Nos trabalho realizados por Shepetina et al., 1986, as sementes de mamona separadas por tamanho também não diferiram em relação à germinação, o vigor e a produtividade. Contudo, as sementes pequenas promoveram maior percentual de emergência, mas em menor velocidade, nos trabalho de Rocha, 1986. Sementes grandes de Schizolobium amazonicum (Huber) Ducke apresentaram melhor germinação que as sementes pequenas, mas não diferiram das sementes de tamanho médio (Ghisolfi et al., 2006). Em cagaiteira (Eugenia dysenterica DC.), sementes maiores propiciaram melhor desenvolvimento inicial de plântulas (Nietsche et al., 2004).

TABELA 1. Primeira contagem (PC), germinação (G) e envelhecimento acelerado (EA) de sementes de quatro cultivares de mamona classificadas por tamanho.

\begin{tabular}{ccccc}
\hline Cultivar & Peneira & PC & G & EA \\
\hline \multirow{2}{*}{ IAC 226 } & $5,25 \times 19$ & $61 \mathrm{a}^{*}$ & $80 \mathrm{a}$ & $34 \mathrm{a}$ \\
& $5,75 \times 19$ & $44 \mathrm{~b}$ & $74 \mathrm{ab}$ & $38 \mathrm{a}$ \\
& $6,25 \times 19$ & $49 \mathrm{~b}$ & $71 \mathrm{~b}$ & $21 \mathrm{~b}$ \\
\hline \multirow{2}{*}{ IAC 80 } & $6,25 \times 19$ & $40 \mathrm{a}$ & $51 \mathrm{~b}$ & $11 \mathrm{a}$ \\
& $7 \times 17$ & $35 \mathrm{a}$ & $51 \mathrm{~b}$ & $13 \mathrm{a}$ \\
& $7,5 \times 19$ & $35 \mathrm{a}$ & $56 \mathrm{a}$ & $15 \mathrm{a}$ \\
\hline \multirow{2}{*}{ BRS 188 Paraguaçu } & 10 & $46 \mathrm{a}$ & $82 \mathrm{a}$ & $36 \mathrm{a}$ \\
& 12 & $30 \mathrm{~b}$ & $80 \mathrm{a}$ & $35 \mathrm{a}$ \\
& 13 & $33 \mathrm{~b}$ & $62 \mathrm{~b}$ & $-* *$ \\
\hline \multirow{2}{*}{ Al Guarany 2002 } & $5,75 \times 19$ & $61 \mathrm{a}$ & $72 \mathrm{a}$ & $24 \mathrm{a}$ \\
& $6,25 \times 19$ & $57 \mathrm{a}$ & $73 \mathrm{a}$ & $22 \mathrm{a}$ \\
\hline CV (\%) medio nas 4 cultivares & $6,50 \times 15$ & $58 \mathrm{a}$ & $72 \mathrm{a}$ & $21 \mathrm{a}$ \\
\hline
\end{tabular}

* Para cada cultivar médias nas colunas seguidas de mesma letra não diferem pelo teste de Tukey a 5\% de probabilidade.

** Insuficiente numero de sementes para realizacao do teste.

Pelos resultados de envelhecimento acelerado, diferenças no vigor foram verificadas apenas nas sementes da cultivar IAC 226 , onde as sementes retidas nas peneiras $5,25 \times 19$ e $5,75 \times 19$ apresentaram maior vigor em relação às de maior tamanho, retidas na peneira 6,25x19 (Tabela 1). Observa-se que as sementes de mamona foram bastante sensíveis às condições de envelhecimento acelerado, pois os valores obtidos para a germinação após o envelhecimento não ultrapassaram $38 \%$.

Quanto ao crescimento das plântulas (Tabela 2), o tamanho das sementes exerceu efeito variável entre as cultivares. Nas cultivares IAC 226, BRS 188 Paraguaçu e AL Guarany 2002 não houve diferenças significativas entre os resultados de crescimento do sistema radicular (CSR) e da parte aérea (CPA) para as sementes de diferentes tamanhos. Contudo, em soja, sementes maiores originaram plântulas com maior desenvolvimento inicial (Singh et al.,1972) o que constitui-se em um fator interessante, uma vez que beneficia a rápida cobertura do solo e o controle de plantas daninhas (Gilioli, 1982).

Por outro lado, na cultivar IAC 80 os resultados de CSR em sementes maiores (peneira 7,5x19) foram menores do que o observado para as sementes da peneira $7 \times 17 \mathrm{~mm}$, não havendo diferenças significativas entre as peneiras quanto ao comprimento de parte aérea massa de matéria fresca e seca (Tabela 2). Severino et al., 2004, também não observou influência do tamanho das sementes de mamona sobre o desenvolvimento inicial de plântulas. No entanto, sementes de mamona, dos híbridos Sara e Lyra, de maior tamanho e mais pesadas resultaram em plântulas mais vigorosas aos sete e 14 dias após a emergência, nos trabalhos de Brum et al., 2008. Sementes de pitanga (Eugenia 
uniflora L.) de tamanho médio e grande apresentam maior desenvolvimento inicial de plântulas (Klein et al., 2007). Sementes de tamarindeiro de massa e dimensões menores apresentaram maior emergência, porém as sementes de maior tamanho proporcionaram plantas de qualidade superior (Pereira et al., 2008).

TABELA 2. Comprimento do sistema radicular (CSR), comprimento de parte aérea (CPA), massa de matéria fresca (MMF) e massa de matéria seca (MMS) de plântulas oriundas de sementes de quatro cultivares de mamona classificadas por tamanho.

\begin{tabular}{|c|c|c|c|c|c|}
\hline Cultivar & Peneira & CSR & CPA & $\mathrm{MMF}$ & MMS \\
\hline \multirow{3}{*}{ IAC 226} & $5,25 \times 19$ & $19,28 \mathrm{a}$ & $16,84 \mathrm{a}$ & $2116 \mathrm{a}$ & $126 \mathrm{a}$ \\
\hline & $5,75 \times 19$ & $17,86 \mathrm{a}$ & $15,93 \mathrm{a}$ & $2192 \mathrm{a}$ & $155 \mathrm{a}$ \\
\hline & $6,25 \times 19$ & 18,3 a & $16,57 \mathrm{a}$ & $2115 \mathrm{a}$ & $119 \mathrm{a}$ \\
\hline \multirow{3}{*}{ IAC 80} & $6,25 \times 19$ & $15,23 \mathrm{ab}$ & 8,66 a & $1239 \mathrm{a}$ & $119 \mathrm{a}$ \\
\hline & $7 \times 17$ & $17,72 \mathrm{a}$ & $10,63 a$ & 726 a & 53 a \\
\hline & $7,5 \times 19$ & $14,28 \mathrm{~b}$ & 9,64 a & $1014 \mathrm{a}$ & 85 a \\
\hline \multirow{3}{*}{ BRS 188 Paraguaçu } & 10 & $19,01 \mathrm{a}$ & $12,92 \mathrm{a}$ & $3221 \mathrm{a}$ & $286 \mathrm{a}$ \\
\hline & 12 & $18,39 \mathrm{a}$ & $8,58 \mathrm{~b}$ & $3774 \mathrm{a}$ & $379 a$ \\
\hline & 13 & $-* *$ & - & - & - \\
\hline \multirow{3}{*}{ Al Guarany 2002} & $5,75 \times 19$ & $17,12 \mathrm{a}$ & $10,95 \mathrm{a}$ & $1554 \mathrm{~b}$ & $124 \mathrm{~b}$ \\
\hline & $6,25 \times 19$ & $16,12 \mathrm{a}$ & $10,53 \mathrm{a}$ & $1886 \mathrm{~b}$ & $136 \mathrm{~b}$ \\
\hline & $6,50 \times 15$ & $15,44 \mathrm{a}$ & 9,76 a & $2921 \mathrm{a}$ & $224 \mathrm{a}$ \\
\hline $\mathrm{CV}(\%)$ medio nas 4 cultivares & & 10,53 & 15,68 & 20,96 & 23,09 \\
\hline
\end{tabular}

* Para cada cultivar médias nas colunas seguidas de mesma letra não diferem pelo teste de Tukey a 5\% de probabilidade.

** Insuficiente numero de sementes para realizacao do teste.

Apenas na cultivar AL Guarany 2002 o tamanho da semente exerceu influência sobre a massa de matéria fresca (MMF) e a massa de matéria seca (MMS). Nesta cultivar, as sementes maiores, retidas na peneira $6,50 \times 15$, geraram plântulas com maior MMF e MMS. No entanto, essa maior biomassa não significa maior taxa de transferência de reservas, uma vez que as plântulas foram pesadas com o endosperma. Ou seja, o maior tamanho de uma semente de mamona, não significa que está gerará plântulas maiores ou mais vigorosas, pois este efeito está condicionado à velocidade de transferência e conversão das reservas em tecido vegetal. Uma possível explicação para a maior taxa de transferência nas sementes menores pode ser a menor distância percorrida pelos hormônios e enzimas para a hidrólise do óleo no endosperma da semente de mamona.

Em milho, o tamanho da semente não interfere na elongação do mesocótilo, a percentagem e a velocidade de emergência. Por outro lado, a utilização de sementes grandes proporciona aumento do crescimento inicial, resultando na obtenção de plantas de milho mais altas e maior acúmulo de fitomassa (Sangoi et al., 2004). Já em trigo, plântulas originadas de sementes grandes apresentaram maior estatura e acumularam mais massa seca, em comparação com plântulas originadas de sementes pequenas (Lafond e Baker, 1986; Grieve e Francois, 1992).

Assim, verifica-se que há diferenças de desempenho fisiológico entre sementes de mamona de diferentes tamanhos e que há uma tendência de as sementes de menor tamanho terem maior qualidade fisiológica.

\section{CONCLUSÕES}

O tamanho das sementes de mamona influencia seu desempenho fisiológico, sendo que nas cultivares IAC 226 e BRS 188 Paraguaçu há tendência de as sementes menores apresentarem maior velocidade e porcentagem final de germinação, o que não ocorre para as cultivares IAC $80 \mathrm{e}$ AL Guarany 2002. 


\section{REFERÊNCIAS}

BRUM, B.; LOPES, S.J.; SILVEIRA, T.R.; TOEBE, M. Relações entre características de sementes e plântulas em dois híbridos de mamona. In: CONGRESSO BRASILEIRO DA MAMONA, 3., 2008, Salvador. Energia e Ricinoquímica Anais... Salvador: SEAGRI: Embrapa Algodão, 2008.

BURRIS, J.S.; EDJE, O.T.; WAHAB, A.H. Effects of seed size in soybeans, II. Growth and photossynthesis and field performance. Crop Science, v.13, p.207-210, 1973.

GHISOLFI, E.M.; EFFGEN, E.M.; MENDONÇA, A.R. de; NAPPO, M.E.; SILVA, A.G. da. Influência do tamanho da semente e tipo de recipiente na germinação de Schizolobium amazonicum (Herb) Ducke. Revista Científica Eletrônica de Agronomia, ano 5, n.9, 2006.

GILIOLI, J.L. Influência do tamanho das sementes sobre algumas características agronômicas da soja. In: SEMINÁRIO NACIONAL DE PESQUISA DA SOJA, 1., 1978, Londrina,. Anais... EMBRAPA - CNPSo, 1982. p.309-315.

GRIEVE, C.M.; FRANCOIS, L.E. The importance of initial seed size in wheat response to salinity. Plant and Soil, v.147, p.197-205, 1992.

HIRSHFIELD, K.M.; FLANNERY, R.L.; DAIE, J. Cotyledon cell number and cell size in relation to seed size and yield of soybean. Plant Physiology and Biochemistry, v.30, n.3, p.395-400, 1993.

KLEIN, J.; ZUCARELI, V.; KESTRING, D.; CAMILLI, L.; RODRIGUES, J.R. Efeito do tamanho da semente na emergência e desenvolvimento inicial de mudas de pitangueira (Eugenia uniflora L.). Revista Brasileira de Biociências, v.5, n.2, p.861-863, 2007.

KOLAK, I.; HENNEBERG, R.; MILAS, S.; RADOSEVIC, J.; SATOVIC, Z. Influence of seed size on yield and yield components in different soybean cultivars. Polioprivredna Znanstvena, v.57, n.3/4, p.519-526, 1992.

KRZYZANOWSKI, F.C.; FRANÇA-NETO, J.B.; COSTA, N.P. Efeito da classificação de sementes de soja por tamanho sobre sua qualidade e a precisão de semeadura. Revista Brasileira de Sementes, v.13, n.1, p.59-68, 1991.

LAFOND, G.P.; BAKER, R.J. Effects of genotype and seed size on speed of emergence and seedling vigor in nine spring wheat cultivars. Crop Science, v.26, p.341-346, 1986.

LIMA, A.M.M.P.; CARMONA, R. Influência do tamanho da semente no desempenho produtivo da soja. Revista Brasileira de Sementes, v.21, n.1, p.157-163, 1999.
MARTINS, C.C.; MACHADO, C.G.; NAKAGAWA, J.; OLIVEIRA, S.S.C. de. Tamanho e secagem de sementes de Palmeira Jussara sobre a germinação e o vigor. Caatinga, v.22, n.2, p.117-120, 2009.

MENDES, R.C. Tratamentos pré-germinativos e avaliação do potencial fisiológico de sementes de mamona. 2007. 62f. Dissertação (Mestrado) - Universidade Federal de Viçosa, Viçosa. 2007.

MIAN, M.A.R.; NAFZIGER, E.D. Seed size and water potential effects on germination and seedling growth of winter wheat. Crop Science, v.34, p.169-171, 1994.

MOHSENIN, N.N. Physical properties of plants and animal materials. New York: Gordon and Breach Publishes. 1970. 742p.

NIETSCHE, S.; GONÇALVES, V.D.; PEREIRA, M.C.T.; SANTOS, F.A.; ABREU, S.C. de; MOTA, W.F. da. Tamanho da semente e substratos na germinação e crescimento inicial de mudas de cagaiteira (Eugenia dysenterica DC.). Ciência e Agrotecnologia, v.28, n.6, p.1321-1325, 2004.

PEREIRA, P.C.; FREITAS, R.S. de; MELO, B. de; FRANZÃO, A.A.; PEREIRA, A.P.; SANTANA, J. das G.; LUZ, J.M.Q.; MARTINS, M. Influência do tamanho de sementes na qualidade de mudas de tamarindeiro. Bioscience Journal, v.24, n.4, p.73-79, 2008.

PETERSON, C.M.; KLEPPER, B.; RICKMAN, R.W. Seed reserves and seedling development in winter wheat. Agronomy Journal, v.81, p.245-251, 1989.

POPINIGIS, F. Fisiologia da semente. Brasília, DF: AGIPLAN, 1977. 289p.

ROCHA, R.C. Comportamento de plântulas de mamona (Ricinus communis L.), em função do tamanho da semente, profundidade de plantio, classe textural e pré-embebição. 1986. 55f. Dissertação (Mestrado) - Universidade Federal do Ceará, Fortaleza. 1986.

SANGOI, L.; ALMEIDA, M.L.; HORN, D.; BIANCHET, P.; GRACIETTI, M.A.; SCHMITT, A.; SCHWEITZER, C. Tamanho de semente, profundidade de semeadura e crescimento inicial do milho em duas épocas de semeadura. Revista Brasileira de Milho e Sorgo, v.3, n.3, p.370-380, 2004.

SAS System for Windows. SAS Versão 9.0, 1998.

SEVERINO, L.S; COELHO. D. K.; CARDOSO, G. D. Caracterização de sementes de mamona em diferentes faixas de peso. In: CONGRESSO BRASILEIRO DA MAMONA, 1., 2004, Campina Grande. Anais eletrônicos... Campina Grande: EMBRAPA, 2004. Disponível em: <http://www. 
cnpa.embrapa.br/produtos/mamona/publicaçoes $>$. Acesso em: 5 nov. 2009.

SHEPETINA, F.A.; SEVAST'YANOVA, L.B. Seed Technology. In: MOSHKIM, V.A. Castor. New Delhi: Amerind Publishing, 1986. p.175-178.

SINGH, J.N.; TRIPTHI, S.K.; NEGI, P.S. Note on the effect of seed size on germination growth and yield of soybeans (Glycine $\max$ (L.) Merr.). Food Agricultural Science, v.42, n.1, p.83-86, 1972.

SIYASUBRAMANIAN, S.; RAMAKRISHNAN, V. Effect of seed size on seedling vigor in groundnut. Seed Science and Technology, v.2, n.3, p.435-441, 1974.

SUNG, F.J.M. Field emergence of edible soybean seeds differing in seed size and emergence strength. Seed Science and Technology, v.20, n.3, p.527-532, 1992.
TINIUS, C.N.; BURTON, J.W.; CARTER, T.E. Recurrent selection for seed size in soybean. Crop Science, v.33, n.5, p.959-962, 1993.

WHITE, J.W.; GONZÁLEZ, A. Characterization of the negative association between seed yield and seed size among genotypes of common bean. Field Crops Research, v.23, p.159-175, 1990.

WHITE, J.W.; SINGH, S.P.; PINO, C.; RIOS, B.M.J.;BUDDENHAGEN, I. Effects of seed size and photoperiod response on crop growth and yield of common bean. Field Crops Research, v.28, p.295-307, 1992.

YAN, X.; LYNCH, J.P.; BEEBE, S.E. Genetic variation for phosphorus efficiency of common bean in contrasting soil types - I: vegetative response. Crop Science, v.35, p.10861093, 1995. 